\title{
Context-dependent taste-aversion learning with a familiar conditioning context
}

\author{
TREVOR ARCHER and PER-OLOW SJÖDÉN \\ Uppsala University, S-75104, Uppsala, Sweden
}

\begin{abstract}
Two experiments were performed to assess the strength of exteroceptive contextual conditioning and extinction effects in the taste-aversion paradigm, employing a familiar conditioning context. Groups of rats $(n=6)$ were given two saccharin $(\mathrm{CS}) /$ lithium chloride (UCS) pairings in a familiar context, consisting of cage, bottle, and odor stimuli. During extinction, saccharin or water was presented to various groups either in the same or in a different context, compared to that used at conditioning. The contextual control of saccharin intake was much less than that found with a novel conditioning context in previous studies. No context specific control of water intake was found. Postextinction saccharin preference tests performed in the presence or absence of the conditioning context indicated extinction to be context specific. These effects were demonstrated both when the extinction period followed immediately after conditioning and after a three-week delay.The data support Mitchell et al.'s two-process theory of taste-aversion learning, according to which an associative CS-UCS component is superimposed upon a neophobic response to the taste + exteroceptive context.
\end{abstract}

Attempts to establish associations between exteroceptive events and nausea in rats have generally not been very successful (Domjan \& Wilson, 1972; Garcia, Kimeldorf, \& Hunt, 1961; Garcia \& Koelling, 1966, 1967; Garcia, McGowan, Ervin, \& Koelling, 1968; Green, Holmstrom, \& Wollman, 1974), whereas interoceptive (taste)-nausea associations have been amply demonstrated (Barker, Best, \& Domjan, 1977; Garcia, Kimeldorf, \& Koelling, 1955; Milgram, Krames, \& Alloway, 1977). In an effort to account for these inconsistencies of stimulus associability, many workers have forwarded "neoevolutionary" theories (for a review, see Revusky, 1977), postulating species-specific mechanisms which selectively facilitate the latter type of associations in rats (e.g., Rozin \& Kalat, 1971; Seligman, 1970; Shettleworth, 1972).

In a recent study (Archer, Sjödén, Nilsson, \& Carter, 1979), we employed a compound stimulus consisting of a novel taste and a novel set of exteroceptive (odor, cage, and bottle) stimuli at conditioning, poisoned the animals, and tested for variations in the strength of the resulting taste aversion in the presence or absence of the exteroceptive conditioning stimuli. The results showed that exteroceptive cues do play an important role in the conditioning and extinction of a taste aversion. Thus, a change of extero-

Thanks are due to G. Ohlin for competent laboratory assistance. The present research was supported by Grants 1128/77 and 963/78 to the second author from the Swedish Council for Research in the Humanities and Social Sciences, and by grants from Uppsala University. Reprints may be obtained from Per-Olow Sjödén, Department of Psychology, Uppsala University, Box 227, S-75104, Uppsala, Sweden. ceptive context from conditioning to extinction resulted in a higher absolute intake of the taste substance than when the conditioning context was maintained. Also, postextinction saccharin preference tests performed in the presence of the conditioning and extinction contexts indicated extinction of the taste-aversion to be context specific; that is, groups given extinction trials in a context different from that of conditioning retained their saccharin aversion in the conditioning context.

In taste-aversion learning, the novelty of the taste stimulus at conditioning is an important determinant of the strength of the resulting aversion. Novel tastes typically yield stronger aversions than familiar tastes (e.g., Revusky \& Bedarf, 1967; Wittlin \& Brookshire, 1968). Mitchell, Kirschbaum, and Perry (1975) have suggested that the differential associability of interoceptive and exteroceptive stimuli with nausea may be due, at least in part, to the fact that familiar exteroceptive stimuli were used in most studies of this phenomenon. By varying the duration of preconditioning exposure to a food container, these authors were able to show toxicosis-induced avoidance of a novel container after only one or two conditioning trials. In line with this result, we employed a novel set of exteroceptive background stimuli during conditioning in our previous study (Archer et al., 1979). In the present experiments, we employed a familiar set of exteroceptive stimuli at conditioning and tested for exteroceptive control of subsequent taste-aversion extinction. A familiar set of exteroceptive stimuli is expected to cause a lesser depression of saccharin intake (i.e., less neophobia) on the conditioning trial than a novel set (Mitchell et al., 1975). Furthermore, if the differential associability of interoceptive and 
exteroceptive events with toxicosis is due to their relative novelty, it may be expected that a familiar set of exteroceptive stimuli should result in a lower degree of exteroceptive control of the taste aversion than a novel set of stimuli.

\section{EXPERIMENT 1}

Experiment 1 was designed to investigate what degree of exteroceptive control of a saccharin aversion would result when a familiar set of exteroceptive stimuli was employed at conditioning. Thus, no exteroceptive contextual changes were introduced at the two saccharin- $\mathrm{LiCl}$ conditioning trials. Subsequent daily extinction trials were performed, at which saccharin was presented to separate groups either in the same contexı as during conditioning (Group SS, see Table 1) or in a different (from conditioning) context (Group DS). A taste-aversion conditioning control group (SC) was given $\mathrm{NaCl}$ instead of $\mathrm{LiCl}$ in order to assess the magnitude of the aversions in the experimental groups. Postextinction preference tests, offering saccharin and water in both types of context to all groups, were performed to assess the effects of contextual manipulations during the extinction phase. A "no-extinction" control group (SW), subjected to two saccharin- $\mathrm{LiCl}$ conditioning trials, but given water only during the extinction phase, was employed to assess the magnitude of the extinction effects in the experimental groups.

\section{Method}

Preconditioning. Twenty-four experimentally naive male Sprague-Dawley rats, aged 60-65 days (AB Anticimex, Sollentuna, Sweden), with a mean body weight of $225 \mathrm{~g}$ (range 200-250 g) were assigned to four groups $(n=6)$, matched for body weight. They were kept on a 12-h-on/12-h-off lighting schedule (lights on at $0800 \mathrm{~h}$ ) in rooms maintained at $22 \pm 1{ }^{\circ} \mathrm{C}$. Two different rooms were used: one in which the rats were placed in an exteroceptive context consisting of standard laboratory ("normal") cages with standard ("silent") fluid bottles (Room 1), and one in which they were placed in opaque ("contextual") compartments with "noisy" bottles and a distinctive odor (Room 2). These experimental contexts are described in detail below.

Food (lab. chow R3, Astra-Ewos, Södertälje, Sweden) was available ad lib throughout the experiment. Water was freely available for 2 weeks after arrival. Following this, the animals received 4 days of adjustment to a $30-\mathrm{min} /$ day $(0800$ to $0830 \mathrm{~h})$ drinking schedule. During laboratory acclimatization and drinking adjustment, all groups were housed in Room 1 in "normal" cages: individual perspex cages $(16.5 \times 22.5 \times 13.5 \mathrm{~cm})$ with gridded metal covers with spaces for food and a water bottle. They received water in "silent" bottles: glass bottles with metal nozzles with a $2-\mathrm{mm}$ aperture at the tip.

Experimental conditions and treatments are outlined in Table 1. All groups were given an equal amount of handling on all days, and all bottles were checked daily and immediately replaced if leakage was detected.

Conditioning. On Days 1 and 2, all groups were given a 30 -min $(0800$ to $0830 \mathrm{~h})$ presentation of a $.2 \%$ saccharin solution in "silent" bottles. Approximately 20 min after the end of the drinking period, Groups DS, SS, and SW (taste-aversion groups, see Table 1) received a $2.5-\mathrm{ml}$ intraperitoneal (i.p.) injection of .15 M lithium chloride (LiCl) (cf. Nachman \& Ashe, 1973). Group SC, serving as a placebo-injected control, received a $2.5-\mathrm{ml}$ i.p. injection of .11 M NaCl. All animals were then returned to their cages.

Extinction. On Day 3 (Extinction 1: El), the rats in Group DS $(\mathrm{D}=$ different context) were placed individually in "contextual" compartments $(15 \times 35 \times 20 \mathrm{~cm})$, consisting of opaque plastic boxes with light excluded by Masonite covers, except for two holes for drinking bottles. Food pellets were placed on the floor. In all subsequent phases and experiments, contextual changes took place at $0800 \mathrm{~h}$, immediately before the initiation of the drinking periods. After having been placed in their compartments, the Group-DS animals were moved to Room 2, smelling distinctly of Vick ointment (Vick Vapo Rub, Richardson-Merrell, London), which was smeared every 2 days on wooden boards adjacent to the compart-

Table 1

Experimental Treatments and Chronology

\begin{tabular}{|c|c|c|c|c|c|}
\hline \multirow[b]{2}{*}{ Group } & \multirow{2}{*}{$\begin{array}{l}\text { Precondi- } \\
\text { tioning }\end{array}$} & \multirow{2}{*}{$\begin{array}{l}\text { Conditioning } \\
\text { Days 1-2 }\end{array}$} & \multirow{2}{*}{$\begin{array}{c}\text { Extinction } \\
\text { Days 3-7† }\end{array}$} & \multicolumn{2}{|c|}{ Preference Tests } \\
\hline & & & & Days $8-9 \dagger \dagger$ & Day 10 \\
\hline \multicolumn{6}{|c|}{ Experiment 1} \\
\hline DS & Norm & Norm, $\mathrm{Sacc}+\mathrm{LiCl}$ & Cont, Sacc & Norm & Cont \\
\hline SS & Norm & Norm, Sacc + LiCl & Norm, Sacc & Norm & Cont \\
\hline SC & Norm & $\mathrm{Norm}, \mathrm{Sacc}+\mathrm{NaCl}$ & Norm, Sacc & Norm & Cont \\
\hline SW & Norm & Norm, Sacc + LiCl & Norm, Water & Norm & Cont \\
\hline \multicolumn{6}{|c|}{ Experiment $2 \mathrm{~A}$} \\
\hline DS & Cont & Cont, $\mathrm{Sacc}+\mathrm{LiCl}$ & Norm, Sacc & Cont & Norm \\
\hline SS & Cont & Cont, Sacc + LiCl & Cont, Sacc & Cont & Norm \\
\hline DW & Cont & Cont, Sacc + $\mathrm{LiCl}$ & Norm, Water & Cont & Norm \\
\hline SW & Cont & Cont, Sacc + LiCl & Cont, Water & Cont & Norm \\
\hline \multicolumn{6}{|c|}{ Experiment 2B } \\
\hline $\mathrm{SW}^{*}$ & & & Cont, Water & Cont & \\
\hline DW* & & & Norm, Water & Cont & \\
\hline SS* & & & Cont, Sacc & Cont & \\
\hline DS* & & & Norm, Sacc & Cont & \\
\hline
\end{tabular}

Note-The following abbreviations are used for describing groups: first letter, $D=$ extinction context different from conditioning context, $S=$ extinction and conditioning contexts the same; second letter, $S=$ saccharin during extinction phase, $C=$ control, $W=$ water during extinction phase. Norm = "normal" cages with "silent" bottles; Cont = "contextual" compartments with "noisy" bottles and mentholated odor. * *See text. TDays 21-25 in Experiment $2 B . \quad$ +tDays 26-27 in Experiment $2 B$. 
ments. Groups SS, SC, and SW (first $\mathrm{S}=$ same context) remained in "normal" cages in Room 1. All animals remained in their respective compartments or cages for $24 \mathrm{~h} /$ day during the extinction period. A .2\% saccharin solution was offered to Groups DS, SS, and SC (second S = saccharin). Groups SS and SC drank from "silent" bottles, whereas Group DS drank from "noisy" bottles with metal nozzles having a 6-mm hole at the tip and containing a small metal ball. The ball created a marked clicking noise and provided tactile feedback contingent on licking. Group SW ( $W=$ water), a no-extinction control group, was of fered water in "silent" bottles. All fluid presentations lasted $30 \mathrm{~min}(0800$ to $0830 \mathrm{~h}$ ). Identical saccharin or water presentations were performed on Days 4-7 (E2-E5).

Preference testing. On Days 8 and 9 (Tests 1 and 2: T1, T2), 8 -h saccharin preference tests $(0800$ to $1600 \mathrm{~h})$ were given, each animal receiving one saccharin and one water "silent" bottle in the conditioning context. Group DS was returned to "normal" cages in Room 1, while the other groups remained in their environments. The positions of the saccharin and water bottles were reversed between days. On Day 10 (T3), a third preference test was given to all groups in a contextual environment different from that of conditioning. Thus, all groups were placed in the "contextual" compartments, moved to Room 2, and offered fluids in "noisy" bottles. It should be noted that this corresponds to the extinction context for Group DS. The percent preference for saccharin in relation to total fluid intake was computed. Throughout, fluid intake was recorded by weighing the bottles to the nearest $1.0 \mathrm{~g}$.

\section{Results and Discussion}

All data were subjected to analysis of variance (Kirk, 1968), based on split-plot designs, with the .05 level of significance adopted throughout. Testing of pairwise differences between groups was performed with the Tukey HSD test using $\mathrm{p}<.01$ throughout. The error term for these comparisons was the withincell variance (Kirk, 1968).

There were no significant differences between groups on the first saccharin exposure, mean values of Day 1 intake being: Group DS, $17.8 \mathrm{~g}$; Group SS, $17.8 \mathrm{~g}$; Group SC, $15.3 \mathrm{~g}$; and Group SW, $18.2 \mathrm{~g}$. Analysis of Day 2 data indicated that Group SC drank significantly more saccharin $(17.0 \mathrm{~g})$ than the remaining groups-DS, $7.3 \mathrm{~g}$; SS, $6.0 \mathrm{~g}$; and SW, $7.5 \mathrm{~g}$-resulting in a significant Groups by Days interaction $[F(3,20)=25.3]$. Thus, saccharin aversions were reliably produced in all experimental groups.

The data from the extinction phase (E1-E5) indicate that the presence or absence of the exteroceptive contextual cues of the conditioning trials exerted at least some control over the amount of saccharin drunk in that there was a significant SS $<$ DS difference for E2 (see Figure 1, left-hand panel). However, this effect is much weaker than the "same""different" context effect for E1-E4 demonstrated in a previous study (Archer et al., 1979), where the exteroceptive stimuli were novel at the conditioning trial. Analysis of variance revealed a Groups by Days interaction $[F(12,80)=7.8]$. Subsequent pairwise testing showed a significantly lower saccharin intake in Groups DS and SS as compared to Group SC (saccharin) and Group SW (water) on E1-E4. Thus, the group removed from the condition-

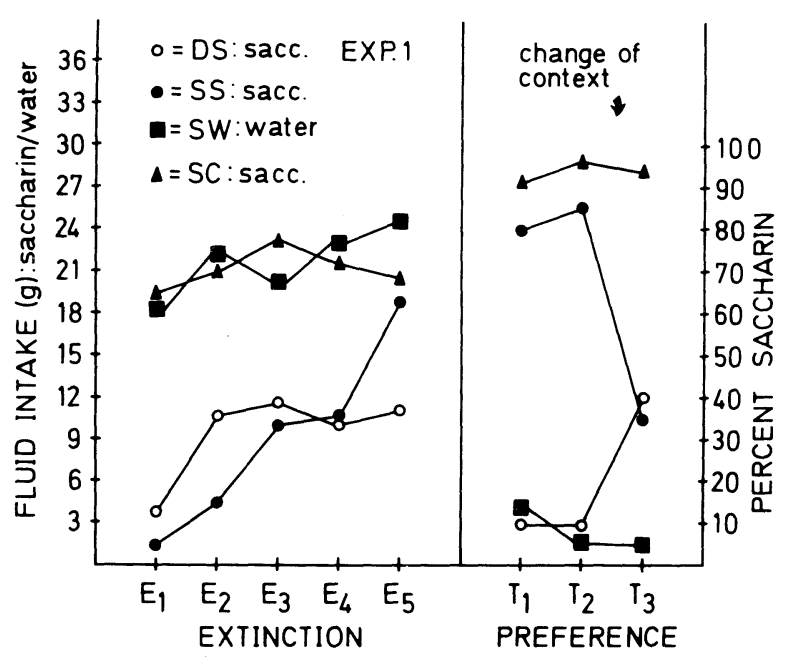

Figure 1. Saccharin or water intake during extinction and percent saccharin preference during preference testing for four groups of rats in Experiment 1. Change of context took place between extinction and testing for Group DS, and between T2 and T3 for all groups.

ing context (DS) also showed a low saccharin intake. This finding differs from that of our previous study (Archer et al., 1979), where no aversion was evident in the "different" context groups during E1-E4. A plausible reason for this discrepancy is that the present DS animals were placed in a completely novel exteroceptive context during extinction, whereas the "different" context groups of our previous study were returned to their preconditioning environment. This suggests that the novel exteroceptive stimuli introduced on E1 suppressed saccharin intake in the DS group (cf. Mitchell et al., 1975).

The preference test data (see Figure 1, right-hand panel) indicate that extinction of the saccharin aversion in a context different from that of conditioning (Group DS) did not result in a decrease of the aversion in the conditioning context (T1 and $\mathrm{T} 2$ ). However, reinstatement of the extinction context for Group DS on T3 yielded evidence of an attenuated aversion. Thus, there was a Groups by Tests interaction $[F(6,40)=12.4]$. Pairwise comparisons revealed the following differences: At $\mathrm{T} 1$ and $\mathrm{T} 2$, Groups DS and SW showed more saccharin aversion than Groups SS and SC. These results indicate that the aversion of the DS animals was as strong as that of the animals (SW) for which water only was present during the extinction phase. Furthermore, a stronger aversion was evident in Group DS than in Group SS, which had consumed saccharin in the conditioning context during the extinction phase.

At T3, when a novel contextual environment was introduced for Groups SS, SC, and SW and the extinction context was reintroduced for Group DS, the latter group showed a lower degree of taste aversion than did Group SW. Also, Group SS showed a sig- 
nificant increase of the aversion from $\mathrm{T} 2$ to $\mathrm{T} 3$. This effect, which we first observed in the two "samecontext" groups in Experiment 2 of our previous study (Archer et al., 1979), probably results from a nonspecific neophobic reaction to the novel "contextual" environment, alternatively interpretable as an instance of Pavlovian disinhibition of the extinguished aversion.

\section{EXPERIMENT 2A}

The data from Experiment 1 suggest a weak exteroceptive control over taste-aversion extinction when a familiar set of exteroceptive stimuli is employed at the conditioning trial. However, during the preference tests, strong exteroceptive control was observed, in spite of the fact that the exteroceptive context was familiar at conditioning. This suggests that the animals in the DS group learned that saccharin is relatively "nonaversive" in the extinction context, and that this experience has very little effect on the aversive properties of saccharin in the conditioning context.

The "contextual" compartment used at conditioning includes stimulus elements which may be particularly salient to the animals (relative darkness, a botthe that provides auditory and tactile stimulation at licking, and a mentholated odor). Therefore, it was judged to be of interest to investigate the possibility that the context-specific effects demonstrated in Group DS of Experiment 1 are particular to the contextual manipulations used. To that end, in Experiment $2 \mathrm{~A}$, the "contextual" environment was used as the preconditioning and conditioning context for all groups. In a recent study (Archer, Sjödén, Nilsson, $\&$ Carter, 1980), we found that a novel set of exteroceptive stimuli introduced at a taste-aversion conditioning trial failed to control subsequent water intake. On the basis of these data, we tentatively suggested that in the presence of the taste (during extinction), there is significant control by exteroceptive stimuli, and in the absence of the taste, there is no exteroceptive control. In an effort to test the generality of this conclusion in Experiment 2, Groups DS, SS, and SW of Experiment 1 were compared to another group, DW, which was offered water during extinction in a "different" (from conditioning) context.

\section{Method}

With the exceptions noted below, the general procedure of Experiment 1 was maintained. Experimental treatments and conditions are summarized in Table 1.

Twenty-four male Sprague-Dawley rats were assigned to four groups $(n=6)$. For 10 days following arrival, all groups were housed in Room 1 (odor-free) in "normal" individual cages and received water in "silent" bottles. Following this, the animals were placed in "contextual" compartments and moved to Room 2 (Vick odor). Here they received water in "noisy" bottles during a 6-day period of adjustment to a 30-min/day drinking schedule.
On Days 1 and 2 (conditioning), all animals remained in compartments in Room 2 and were offered a .2\% saccharin solution for $30 \mathrm{~min}$, followed by a $\mathrm{LiCl}$ injection. On Day 3 (E1), the "different" context groups, DS and DW, were placed in "normal" cages in Room 1, and received fluid presentations in "silent" bottles. Groups DS and SS were offered saccharin, while Groups DW and SW were offered water. Saccharin or water presentations were made under the identical contextual conditions on Days 4-7 (E2-E5). On Days 8 and 9 (T1 and T2), Groups DS and DW were replaced in the "contextual" compartments in Room 2, and all groups received 8-h saccharin preference tests in the conditioning context. On Day 10 (T3), a preference test was given to all groups in Room 1 in the extinction context of Groups DS and DW.

\section{Results and Discussion}

There were no significant between-group differences in the amount of saccharin consumed on Days 1 and 2 , mean values ranging from 10.8 to $14.0 \mathrm{~g}$ on Day 1 and from 7.3 to 8.3 on Day 2. All groups drank significantly less saccharin on Day 2, resulting in a significant Days effect $[F(1,20)=31.0]$. Thus, saccharin aversions were produced in all groups.

The data from the extinction phase (see Figure 2, left-hand panel) indicate that the presence of the conditioning context resulted in a lower saccharin intake than when the conditioning context was absent. No such effect of the conditioning context was evident in the taste-absent conditions. Analysis of variance resulted in a significant Groups by Days interaction $[F(12,80)=8.2]$. Subsequent testing of pairwise differences indicated that Groups DS and SS (saccharin) drank less than Groups DW and SW (water) on E1; Group SS (same context) drank less than Groups DS (different context), SW, and DW on E2; and SS drank less than SW on E3. These data confirm those of Experiment 1 by showing a context-dependent effect only during intermediate stages of extinction

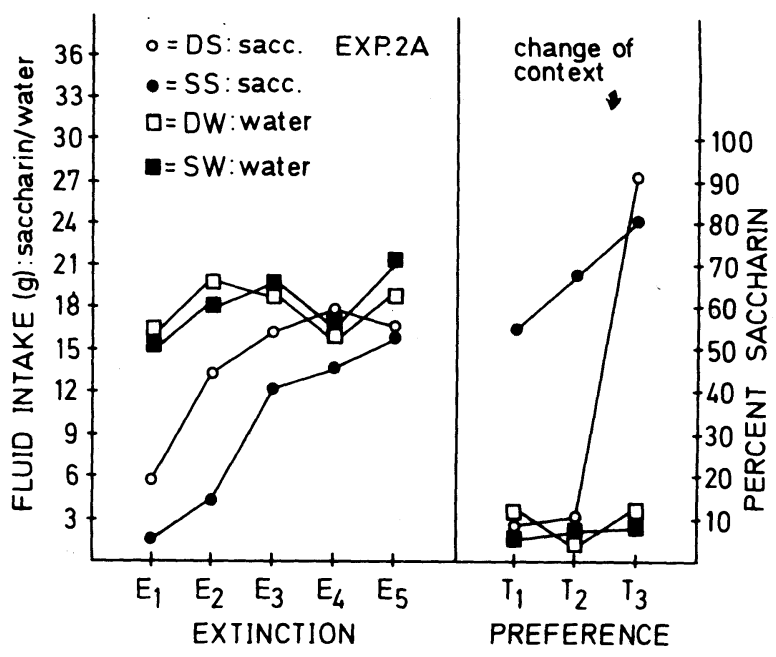

Figure 2. Saccharin or water intake during extinction and percent saccharin preference during preference testing for four groups of rats in Experiment $2 \mathrm{~A}$. Change of context took place between extinction and testing for Groups DS and DW, and between T2 and $\mathrm{T} 3$ for all groups. 
(E2). Also, they confirm previous findings (Archer et al., 1980) by indicating that context-dependent effects seem to require the presence of the taste stimulus.

The preference-test data (see Figure 2, right-hand panel) also confirm the results of Experiment 1 in that the group (SS) that drank saccharin in the conditioning context showed very little saccharin aversion on $\mathrm{T} 1$ and $\mathrm{T} 2$, which were performed in the conditioning context. However, Group DS, which consumed saccharin during the extinction phase in a context different from that of conditioning, demonstrated considerable aversion on $\mathrm{T} 1$ and $\mathrm{T} 2$. Additionally, on $\mathrm{T} 1$ and $\mathrm{T} 2$, there were no differences between the groups that consumed water in the "same" (SW) or "different" contexts (DW) during the extinction phase. Analysis of variance showed a Groups by Tests interaction $[F(6,40)=47.0]$. Pairwise testing revealed that Groups DS, DW, and SW showed greater aversions than did Group SS on T1 and $\mathrm{T} 2$. On T3, both water groups (DW, SW) showed stronger aversions than did the saccharin groups (DS, SS).

The results of Experiment 2A warrant the following conclusions: (1) the context-dependent effects found in Experiment 1 are not peculiar to the contextual manipulations employed in that experiment; (2) the demonstration of strong exteroceptive control over saccharin intake during the extinction phase seems to require that (a) the exteroceptive stimuli be novel at the conditioning trial, and (b) the taste stimulus be present during extinction.

\section{EXPERIMENT 2B}

Experiment 2B consists of a continuation of Experiment $2 \mathrm{~A}$ in that the same groups of animals were employed. Here we aimed to assess whether the context-dependent extinction effects revealed by preference testing could be demonstrated following a longer interval between conditioning and extinction or whether they were transient phenomena. To this end, the groups of Experiment 2A were completely rotated with respect to "same" or "different" contexts and fluids during the extinction phase so that the SW group of Experiment $2 \mathrm{~A}$ became the DS* group in the present experiment, DW became SS*, SS became $\mathrm{DW}^{*}$, and DS became SW*. As can be seen from Figure 2 (right-hand panel), the water groups (DW, SW) of Experiment 2A showed strong and almost identical degrees of aversion during all of preference testing. Therefore, an investigation of the stability of context-dependent effects can be carried out by presenting saccharin during a second extinction period to the previous water groups with one of the groups serving as a "same" context condition and one as a "different" (compared to that of orig- inal conditioning) context condition. In order to facilitate comparison of results between Experiments $2 \mathrm{~A}$ and $2 \mathrm{~B}$, the symbols employed for the separate groups in Figure 2 are used for the presentation in Figure 3 (see below) such that a certain group of animals is designated by the same symbol throughout, although its label changes between experiments.

\section{Method}

Following the last preference test (T3) of Experiment 2A (Day 10), all animals remained in cages in Room 1 and were given free access to water in "silent"' bottles for 10 days. On Day 20, the bottles were removed. Experimental conditions and treatments are summarized in Table 1.

On Day 21 (E1), a second 5-day extinction phase was initiated, and the groups that were to serve in the "same" context condition (SW*, SS*) were placed in the compartments in Room 2 and received fluid presentations in the "noisy" bottles. Groups SS* and DS* were offered saccharin and Groups SW* and DW* were offered water for $30 \mathrm{~min}$. Thus, Groups $\mathrm{SW}^{*}$ and SS* were given extinction trials in the conditioning context, whereas Groups DW* and DS* received extinction trials in a "different" context. Identical contextual conditions and fluid presentations were maintained on Days 22-25 (E2-E5). On Days 26 and 27 (T1, T2), Groups DW* and DS* were placed in the compartments in Room 2 and all groups received 8 -h saccharin preference tests in the conditioning context.

\section{Results and Discussion}

The results of the extinction phase (see Figure 3, left-hand panel) indicate a context-dependent saccharin aversion on E2. Thus, analysis of variance evidenced a significant Groups by Days interaction $[F(12,80)=9.5]$. Subsequent pairwise testing showed that the saccharin groups (SS*, DS*) drank less than the water groups (SW*, DW*) on E1 and E2, and that Group DS*, placed in a context different from

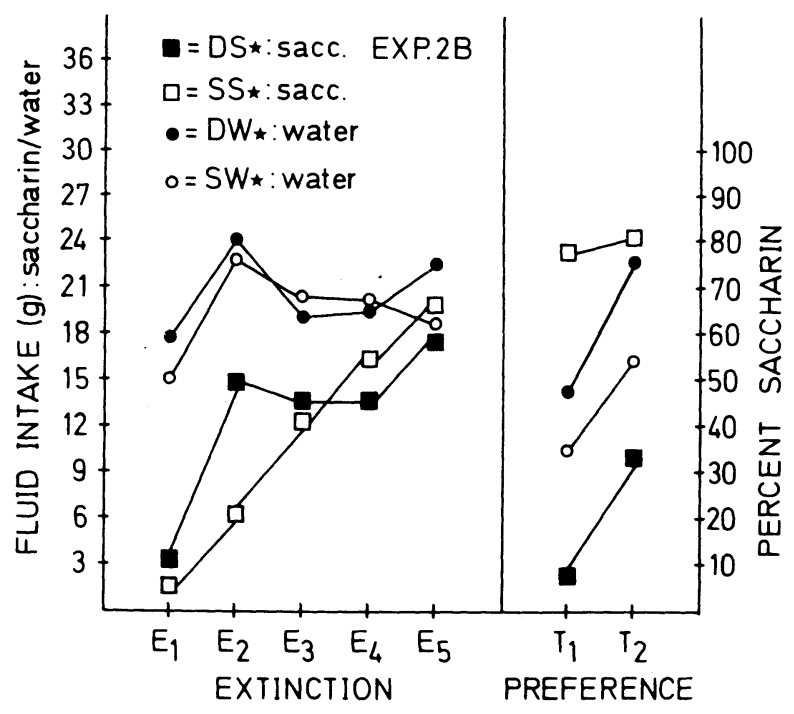

Figure 3. Saccharin or water intake during extinction and percent saccharin preference during preference testing for four groups of rats in Experiment 2B. Change of context took place between extinction and testing for Groups DW* and DS*. 
that of conditioning, drank more saccharin on E2 than Group SS*, which was placed in the conditioning context.

The preference-test data (see Figure 3, right-hand panel) confirm the results of Experiment $2 \mathrm{~A}$ in that Group SS*, which drank saccharin in the conditioning context during extinction, showed almost no aversion, in marked contrast to the strong aversion of Group DS*, which drank saccharin in a "different" context during extinction. Analysis of variance yielded a significant Groups effect $[F(3,20)=6.0]$. Subsequent pairwise testing indicated that Group DS* showed a significantly greater aversion than Group SS*. Furthermore, testing of a combination of the "different"'-context groups (SW*, which served as Group DS in Experiment 2A, + DS*) against the "same"-context groups combination (DW*, serving as Group SS in Experiment 2A, + SS*), using Scheffé's test (Kirk, 1968, p. 90), indicated a stronger aversion by the former combination $(p<.05)$. Thus, the data indicate a reliable context effect in spite of an interval of 19 days between conditioning and extinction. It can therefore be concluded that the tastepresent context-dependent effect is a highly stable phenomenon.

\section{GENERAL DISCUSSION}

The results of the present experiments extend our previous findings (Archer et al., 1979) in the following ways: (1) Extinction phase: (a) The presence or absence of a familiar exteroceptive conditioning context controls saccharin intake during extinction to a lesser degree than when a novel exteroceptive conditioning context is used. (b) Exteroceptive control of fluid intake requires the presence of the taste CS at testing. (2) Preference tests: The presence or absence of the exteroceptive conditioning context during the extinction phase markedly influences the strength of saccharin aversion on subsequent preference tests, although the aversion was established in a familiar conditioning context. (3) Both phases: (a) The effects demonstrated are not particular to either the "normal" or "contextual" conditioning contexts, but can be shown with both. (b) What the animal learns about the exteroceptive conditioning context influences extinction- and preference-test values obtained 19-25 days after conditioning. Thus, contextdependent effects represent a highly stable phenomenon.

It has been proposed that taste-aversion learning has several unique properties which distinguish it from other learning paradigms (e.g., Kalat, 1977). Among these properties are that rats "tend to ignore external events" when faced with a taste-nausea contingency (Revusky \& Garcia, 1970, p. 22; see also Garcia, Hankins, \& Rusiniak, 1974; Garcia, McGowan,
\& Green, 1972; Rozin \& Kalat, 1971), and that tasteaversion learning, in contrast to other types of learning, generalizes readily to a new environment (Garcia, Kovner, \& Green, 1970). The present findings contradict both of these propositions and support our previous argument that rats "do learn about the background context as well as the taste stimulus in tasteaversion conditioning"' (Archer et al., 1979, p. 21). Furthermore, the data raise the following questions: Under what conditions do rats learn about the exteroceptive context, and, about what exteroceptive stimuli do they learn?

Recent findings (Galef \& Osborne, 1978) indicate that the presence of a novel taste stimulus at the conditioning trial is necessary to establish avoidance of visually distinctive food objects. Our present data suggest that novelty is essential also with respect to the exteroceptive stimuli themselves. However, the extinction data do not unequivocally imply that rats do not learn about a familiar conditioning context in contrast to a novel one. The demonstration of exteroceptive control over saccharin intake during the extinction phase rests upon a comparison of "same" and "different" context groups. Thus, if the extinction values for the "different" context groups are low because a novel context was introduced on E1, the lack of significant "same" < "different" effects could be attributed partly to the novelty-familiarity aspect of the extinction context (cf. Mitchell et al., 1975). Conversely, the large "same" < "different" effects obtained with a novel conditioning context (Archer \& Sjödén, 1979a, 1979b; Archer et al., 1979) may be inflated, since the "different" context groups in these experiments were placed in a previously familiar context during extinction.

The finding of context-dependent extinction effects on the preference tests irrespective of the relative novelty of the exteroceptive conditioning context could be taken as an indication that the animals learn about a familiar conditioning context as well as a novel one. Otherwise, the low preference values of the DS groups on T1 and T2 and their dramatic increase on $\mathrm{T} 3$ become difficult to explain, unless the animals learned, at conditioning, that "saccharin is aversive in all contexts" and, at extinction, "but not in this context." The context-dependent effect shown on E2 in both experiments makes the latter line of reasoning untenable: if the animals learned at conditioning that saccharin is aversive in all contexts, there would be no DS $>$ SS difference. Thus, we tentatively conclude that rats learn about a familiar as well as a novel exteroceptive context at conditioning, but that the control exerted by a novel context is stronger than that exerted by a familiar one. Further research, controlling for the relative familiarity of the extinction context in D groups, is necessary to settle this issue. 
In order to account for the stronger control over subsequent saccharin intake exerted by a novel conditioning context (Archer et al., 1979) as compared to a familiar one, we propose that a neophobic response to the taste + exteroceptive context (as evidenced by a depression of fluid intake) mediates these effects. Mitchell and his collaborators (e.g., Mitchell, Parker, \& Johnson, 1976) have previously suggested a similar argument to account for the findings that (1) a novel taste stimulus exerts stronger control over postconditioning fluid intake than a familiar one, and (2) the relative novelty of exteroceptive stimuli is a strong determinant of their associability with illness (Mitchell et al., 1975). The present findings further support Mitchell et al.'s two-process theory of tasteaversion learning according to which an associative CS-UCS component is superimposed upon a neophobic response to the taste + exteroceptive context. Moreover, we suggest that the animal brings to the learning situation, not an "associative apparatus" (Seligman \& Hager, 1972, p. 3) which has ecologically determined, species-specific characteristics, but, rather, a tendency to react with withdrawal and disruption of ongoing behavioral sequences when novel stimuli are presented. It is suggested that the question of "preparedness" (Seligman, 1970) is not so much concerned with learning (associative) mechanisms as with unconditioned responses. We have recently obtained further data supporting this line of reasoning (Archer \& Sjödén, 1979a, 1979b).

\section{REFERENCES}

Archer, T., \& Suödén, P. O. Positive correlation between preand postconditioning saccharin intake in taste aversion learning. Animal Learning \& Behavior, 1979, 7, 144-148. (a)

Archer, T., \& SJödÉn, P. O. Neophobia in taste-aversion conditioning: Individual differences and effects of contextual changes. Physiological Psychology, 1979, 7, 364-369. (b)

Archer, T., Suödén, P. O., Nilsson, L.-G., \& Carter, N. Role of exteroceptive background context in taste-aversion conditioning and extinction. Animal Learning \& Behavior, 1979, 7, 17-22.

Archer, T., Suödén, P. O., Nilsson, L.-G., \& Carter, N. Exteroceptive context in taste-aversion conditioning and extinction: Odour, cage, and bottle stimuli. Quarterly Journal of Experimental Psychology, 1980, in press.

Barker, L. M., Best, M. R., \& Domjan, M. Learning mechanisms in food selection: Waco, Tex: Baylor University Press, 1977.

Domjan, M., \& Wilson, N. E. Specificity of cue to consequence in aversion learning in the rat. Psychonomic Science, 1972, 26, 143-145.

Galef, B. G., JR., \& Osborne, B. Novel taste facilitation of the association of visual cues with toxicosis in rats. Journal of Comparative and Physiological Psychology, 1978, 92, 907-916.

Garcia, J., Hankins, W. G., \& Rusiniak, K. W. Behavioral regulation of the milieu interne in man and rat. Science, 1974, $185,823-831$.

Garcia, J., Kimeldorf, D. J., \& Hunt, E. L. The use of ioniz- ing radiation as a motivating stimulus. Psychological Review, 1961, 68, 383-395.

Garcia, J., Kimeldorf, D. J., \& Koelling, R. A. Conditioned aversion to saccharin resulting from exposure to gamma radiation. Science, 1955, 122, 157-158.

Garcia, J., \& Koelling, R. A. Relation of cue to consequence in avoidance learning. Psychonomic Science, 1966, 4, 123-124.

Garcia, J., \& Koelling, R. A. A comparison of aversions induced by $\mathrm{X}$-rays, toxins, and drugs in the rat. Radiation Research Supplement, 1967, 7, 439-450.

Garcia, J., Kovner, R., \& Green, K. F. Cue properties vs. palatability of flavors in avoidance learning. Psychonomic Science, 1970, 20, 313-314.

Garcia, J., McGowan, B. K., Ervin, F. R., \& Koelling, R. A. Cues: Their relative effectiveness as a function of the reinforcer. Science, 1968, 160, 794-795.

Garcia, J., McGowan, B. K., \& Green, K. F. Biological constraints on conditioning. In M. E. P. Seligman \& J. L. Hager (Eds.), Biological boundaries of learning. New York: AppletonCentury-Crofts, 1972.

Green, K. F., Holmstrom, L. S., \& Wollman, M. A. Relation of cue to consequence in rats: Effect of recuperation from illness. Behavioral Biology, 1974, 10, 491-503.

KALAT, J. W. Biological significance of food aversion learning. In N. W. Milgram, L. Krames, \& T. M. Alloway (Eds.), Food aversion learning. New York: Plenum Press, 1977.

KIRK, R. E. Experimental design: Procedures for the behavioral sciences. Belmont, Calif: Brooks/Cole, 1968.

Milgram, N. W., Krames, L., \& Alloway, T. M. Food aversion learning. New York: Plenum Press, 1977.

Mitchell, D., Kirschbaum, E. H., \& Perry, R. L. Effects of neophobia and habituation on the poison-induced avoidance of exteroceptive stimuli in the rat. Journal of Experimental Psychology: Animal Behavior Processes, 1975, 104, 47-55.

Mitchell, D., Parker, L. F., \& Johnson, R. Absence of a generalization decrement in the poison-induced avoidance of interoceptive stimuli in the rat. Physiological Psychology, 1976, 4, 121-123.

Nachman, M., \& Ashe, J. H. Learned taste aversions in rats as a function of dosage, concentration and route of administration of LiCl. Physiology \& Behavior, 1973, 10, 73-78.

REVUSKY, S. Learning as a general process with emphasis on data from feeding experiments. In N. W. Milgram, L. Krames, \& T. M. Alloway (Eds.), Food aversion learning. New York: Plenum Press, 1977.

REVUSKy, S., \& BEDARF, E. W. Association of illness with ingestion of novel foods. Science, 1967, 155, 219-220.

Revusky, S. H., \& Garcia, J. Learned associations over long delays. In G. H. Bower \& J. T. Spence (Eds.), The psychology of learning and motivation: Advances in research and theory (Vol. 4). New York: Academic Press, 1970.

Rozin, P., \& Kalat, J. W. Specific hungers and poison avoidance as adaptive specializations of learning. Psychological Review, 1971, 78, 459-486.

Seligman, M. E. P. On the generality of the laws of learning. Psychological Review, 1970, 77, 400-418.

Seligman, M. E. P., \& Hager, J. L. Biological boundaries of of learning. New York: Appleton-Century-Crofts, 1972.

Shettleworth, S. J. Constraints on learning. In D. S. Lehrman, R. S. Hinde, \& E. Shaw (Eds.), Advances in the study of behavior (Vol. 4). New York: Academic Press, 1972.

Wittlin, W. A., \& Brookshire, K. H. Apomorphine-induced conditioned aversion to a novel food. Psychonomic Science, $1968,12,217-218$.

(Received for publication December 4, 1979; revision accepted January 30,1980 .) 